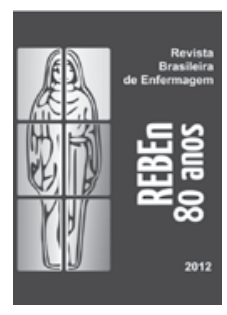

\title{
Sobre a identidade profissional na Enfermagem: reconsiderações pontuais em visão filosófica
}

\author{
About the professional identity in Nursing: punctual reconsiderations in philosophical vision \\ Sobre la identidad profesional en la Enfermería: reconsideraciones puntuales en visión filosófica
}

\begin{abstract}
Vilma de Carvalho'
' Universidade Federal do Rio de Janeiro, Escola de Enfermagem Anna Nery,

Departamento de Enfermagem e Saúde Pública. Rio de Janeiro-RJ, Brasil.
\end{abstract}

Submissão: 10-07-2013 Aprovação: 10-07-2013

RESUMO

Trata-se, neste artigo, de contribuição aos 80 anos da Revista Brasileira de Enfermagem, órgão oficial da Associação Brasileira de Enfermagem (ABEn), antes designado Annaes de Enfermagem e criado em maio de 1932. À época, valeram os propósitos de assegurar a divulgação de assuntos e interesses da Classe Profissional entre os associados, e entre a entidade - Associação Nacional de Enfermeiras Diplomadas Brasileiras (ANEDB) - e o público em geral. Assim, impulsionou-se a liderança associativa aliada aos avanços profissionais e à gênese de produções pertinentes ao Saber/Conhecimento, à educação e prática assistencial de Enfermagem. O trabalho foi escrito com abordagem em discussão e apreciação analítica sobre a identidade profissional mirada em reconsiderações pontuais e visão filosófica. Ao invés de protocolos de investigação, a autora se destaca pelo estilo pragmático tomando três exemplos de situações-problema da prática, como eixos para apreciação crítica sobre a arte de enfermeira e definição do perfil profissional na trajetória histórico-evolutiva - com início na modernidade nightingaleana e conceitos advindos de proposições parsonianas -, como referenciados na Enfermagem brasileira. Sem esgotar o assunto, apenas as questões pertinentes são levantadas.

Descritores: Enfermagem; Identidade Profissional; Arte de Enfermeira.

\begin{abstract}
This paper is a contribution to the $80^{\text {th }}$ years of the Brazilian Nursing Journal, official journal of the Brazilian Nurses Association, first nominated Nursing Annals and created in May 1932. At that time, the issues were focused as proposals to assure exchange communication between the Professional Class - the National Brazilian Graduate Nurses Association - and the associates, including all the people. In this way, the associate leaders were impelled through professional advances allied to the knowledge production regarding to the Professional Know/Knowledge, the practice assistance and education. The approach is through discussion and analytical appreciation about professional identity with punctual reconsiderations in philosophical vision. Instead of researching parameters the author prefers a pragmatic style around examples of three situations-problem as succeeded in the practical assistance, so that they could be critically appreciated alike fundamental basis to the nurses' art and enough to assure the definition of the professional profile in the historical-evolutive trajectory - with beginning in the nightingalean modernity and the proper assumed parsonian concepts - as such they are observed in the Brazilian Nursing literature. Without through off the subject, only the specific questions are submitted.
\end{abstract}

Key words: Nursing; Professional Identity; Nurse Art. 


\section{RESUMEN}

Este artículo es una contribución a los 80 años de la Revista Brasileña de Enfermería, órgano oficial de la Asociación Brasileña de Enfermería (ABEn), revista antes Ilamada Annaes de Enfermería y criada en Mayo de 1932. En esta época, fueron atendidos los propósitos de asegurar la divulgación de temas de interese de la Clase Profesional entre los asociados, y entre la entidad - Asociación Nacional de Enfermeras Diplomadas Brasileñas (ANEDB) - y el público en general. Así, se avanzó la liderazgo asociativa a los adelantes profesionales y a la génesis de producciones al Saber/Conocimiento, la educación y la práctica asistencial de enfermería. El artículo fue escrito con enfoque a la discusión y evaluación analítica de la identidad profesional, orientado a reconsideraciones filosóficas específicas. En lugar de protocolos de investigación, la autora se destaca por lo estilo pragmático tomando ejemplos de situaciones-problema de la práctica, como ejes para apreciación crítica sobre la arte de la enfermera y la definición del perfil profesional en la trayectoria histórica y evolutivo - iniciando en la modernidad nightingaleana y los conceptos parsonianos -, como son referenciados en la Enfermería brasileña. Sin agotar el asunto, solamente las questiones de pertinencia son levantadas.

Palabras clave: Enfermería; Identidad Profesional; Arte de la Enfermera.

\section{AUTOR CORRESPONDENTE Vilma de Carvalho E-mail: decarvalho.vilma@gmail.com}

\section{ESCLARECIMENTOS PRELIMINARES}

Este tema é uma contribuição à Revista Brasileira de Enfermagem (REBEn), órgão oficial da Associação Brasileira de Enfermagem (ABEn Nacional), criado em Maio de 1932 como Annaes de Enfermagem, para divulgação de assuntos da Classe Profissional entre os associados, e entre a própria entidade, então Associação Nacional de Enfermeiras Diplomadas Brasileiras (ANEDB), e o público em geral. A Redatora-Chefe Rachel Haddock Lobo, era então Diretora da Escola de Enfermagem Anna Nery, e deu impulso aos avanços profissionais e à gênese de produções da educação da enfermeira e prática assistencial, na realidade brasileira. Dado o interesse associativo, estabeleceu-se a comunicação efetiva e sedimentou-se verdadeira contribuição de valor insigne ao patrimônio histórico do Saber/Conhecimento Profissional. Sendo agora, a REBEn, um instrumento de comunicação associativa valioso e com já completos 80 anos de bons serviços prestados à sociedade em âmbito cultural e profissional.

Desde o começo e cerca de dois decênios adiante, as publicações em Annaes de Enfermagem versaram sobre tópicos relacionados à “Enfermagem e História - disciplinas de formação profissional, condutas técnicas, comportamentos morais e éticos, característica do perfil e competências da responsabilidade social da enfermeira"(1). Com erudição simples, sem maior preocupação metodológica, as publicações consagram, em progresso e avanços, o Saber/Conhecimento no interesse dos profissionais. Porque a intencionalidade associativa é notória, sobremodo, primando pelo cultivo de significados e atributos da identidade da enfermeira, interesse pontual do que se deve esperar da educação e prática profissional na Enfermagem.

O propósito primaz é o de conferir a problemática da Identidade Profissional na Enfermagem, à conta das crises que afetam em tipo de globalização e competitividade todo o viver e o conviver - a vida, trabalho, objetivos profissionais, intercomunicação $^{(2)}$. Na abordagem, a ideia norte visa o perfil da enfermeira em ângulo de análise crítica. Em plano de reconsiderações pontuais, não sigo por via de buscas investigativas e tampouco com pretensão de esgotar o tema quanto à definição de enfermeira. Embora com muito a dizer, a exiguidade de tempo é um fato, e pelo que sei permito-me endereçar os leitores aos registros e referências para o Saber/Conhecimento Profissional. As produções na REBEn são fartas. Mas, como devo esta contribuição a uma solicitação da $A B E n$, convido os interessados na profissão a ocupar um pouco de seu tempo e atender às reflexões sobre contingências do papel e posição da enfermeira nos programas relativos à assistência de enfermagem.

Para reconsiderações pontuais, tenha-se em conta turbulências mundiais e também crises histórico-evolutivas, as quais, em mudanças de época e na atualidade, distorcem em si e por si, a identidade da enfermeira. Das crises não escapam a essencialidade dos traços da prática assistencial, na Saúde e na Enfermagem. Tudo muda à nossa volta e em nós mesmos, tudo vai de roldão com o pensamento em crise, incluída a compreendida e assumida identidade profissional. Exemplos de adversidades na prática da Saúde e na Enfermagem, lamentavelmente constam de informações ao público - jornais e noticiário de alta definição (TV, Internet, etc.). Considere-se tudo às claras, as distorções conceituais afetam perfil e papel profissional aliados aos cuidados de enfermagem, sem subterfúgios nas situações assistenciais adversas - negligências, omissões, erros técnicos, falhas humanas, falta de vigilância - sucedâneas nos Serviços do Sistema de Saúde (SUS). Quando não plenamente nocivas, nas contingências de programas de acesso ao bem-estar, essas situações apelam soluções eficazes, que raramente alcançam as precárias condições do trabalho humano, péssimas instâncias de infra-estrutura, planos desorganizados de gerenciamento mal formalizado, nas instituições de saúde, em âmbito real do que se compreende por prática de risco.

\section{DOS PROPÓSITOS DE UMA DISCUSSÃO EM ESTILO PRAGMÁTICO}

Consideramos, aqui, exemplos de situações-problema da prática assistencial de enfermagem, com nocivas condições contrárias à adequação do que se assume como $A$ Arte da Enfermagem - efêmera, graciosa, e perene ${ }^{(3)}$. Na atuação profissional precária e sucedânea às repercussões adversas aos cuidados 
prestados aos clientes, os graus de complexidade emergem não das situações em si, mas da qualidade da interação humana ${ }^{(4)}$; e, com efeito, tangíveis à inadequabilidade da própria assistência de enfermagem. Os graus de complexidade não surgem por acaso; em sua maioria, surgem de distorções assistenciais e da formalização incorreta da atuação da enfermeira. Nesta discussão, tomamos exemplos de situações adversas de clientes e com atuação profissional complicada, a partir de descrições em trabalho apresentado no $10^{\circ}$ SENPE (Gramado RS 1999), quando se discutem nocivas condições situacionais ${ }^{(5)}$, mais sérias pelo sobrepeso impróprio à atuação de enfermeiras/os, e visando aplicar às mesmas as leis da arte (Lex-Art na expressão latina). Seguindo o propósito primaz do pensamento sobre Enfermagem, às ditas situações de enfermagem são aplicadas as leis da Filosofia da $\operatorname{Arte}^{(6)}$, com intenção epistemológica de propiciar apoio à fiscalização da atuação profissional, em âmbito de prática de risco. Vejam-se os exemplos, a seguir.

\section{Quadro 1 - "Clientes Expostos"}

Os clientes passam algumas vezes ao dia no corredor, para tomar o banho ou ir ao sanitário... O banheiro é distante de seus leitos... O que chama a atenção é que eles estão quase sempre nus e com as nádegas expostas... Os transeuntes (da Enfermagem) parecem não se incomodar, tudo é normal... Os clientes demonstram, através de expressão corporal, desconforto e vergonha... Porém, não reclamam, - parecem com medo -, e não falam... [Mas o corpo fala!]... Ao perguntar-se à Enfermagem porque eles não são protegidos, não sabem responder... (As evasivas: - "quando cheguei aqui já era assim"... "os clientes não reclamam"... "quem quiser que não olhe para eles"... ).

Quadro 2 - "Injetando ar no corpo"

Os alunos de enfermagem se deparam com um procedimento que não aprenderam... Após a alimentação de um bebê, em uso de sonda nasogástrica, ao invés de introduzir água para lavá-la de acordo com orientação recebida, estão injetando ar... (Os bebês ficam agitados e com abdomens distendidos)... Para aliviar o desconforto, a enfermagem coloca sonda retal... Os alunos assustados perguntam: "Por que isso?" Alguém responde: "Foi o doutor que mandou"... (Mas a ordem não consta na prescrição)

Quadro 3 - "Passando o plantão no elevador"

Enfermeira $\mathbf{Y}$, no elevador, fala para a colega $\mathbf{Z}$ que está chegando (para plantão noturno): "Estou com um cliente confuso que acaba de chegar... Não sei o que ele tem, veja, para mim, pois eu já devia estar no outro emprego"... A enfermeira da noite não pergunta o nome do cliente, e vai para a sala de supervisão receber o relatório do serviço, onde essa situação não está registrada/informada... Durante a noite, a mesma é solicitada a ver um cliente "confuso", o qual se suicidou pulando a janela... (No plantão seguinte, ela descobre que se tratava do mesmo cliente).
Com efeito, não dá para realizar, aqui, uma crítica tipo empírica - comparação ou controle - de ciência por evidências. Também não dá para tratar da aplicação da Lex-Art à Arte da Enfermagem, pois não é objeto do assunto em pauta (endereçamos os interessados às referências 5 e 6). Nesta oportunidade, procede-se à apreciação de impressões e percepções de fatos fenomenicamente dados à visão de qualquer enfermeira particularmente atenta aos fundamentos básicos de sua arte e, pois, assim comprometida com atributos de responsabilidades peculiares ao bem-estar daqueles sob os cuidados de enfermagem.

Assim, da primeira situação - Exemplo 1 "Clientes expostos" - se pode afirmar: um típico atentado às atitudes, condutas técnicas e profissionalismo ético-estético como observados frente à essência significativa da arte da enfermeira e como disposta em "Notes on Nursing: what it is and what it is not"(7). Então, uma radical contradição à "racionalidade de atividades da atuação da enfermeira no âmbito da Assistência de Enfermagem"(8). Não só diante de exemplar Ética Profissional $^{(9)}$ e valores - humanísticos e deontológicos -, remanescentes de ordem cristã tradicional, mas porque "adstrictus aos Princípios Básicos de Cuidados de Enfermagem"(10). Dos "deveres da enfermeira" constam em regras legais "respeitar o pudor, a privacidade e a intimidade do ser humano em todo o ciclo vital"(9). Pelos atos e operações do estilo da Enfermagem como arte de cuidar de clientes, e objetivos de estratégias assistenciais, condutas estéticas, jamais se deve esquecer a utilidade pragmática da função da enfermeira: - "o profissional de enfermagem exerce suas atividades com competência para a promoção do ser humano na sua integralidade, de acordo com os princípios da ética e da bioética"(9). Tampouco se deve esquecer o valor científico e social do que-fazer, mormente se a enfermeira é detentora do poder de intervir com decisões em plano de responsabilidades na provisão e distribuição de cuidados de enfermagem em âmbito de prática assistencial( ${ }^{(8)}$.

Sobre o Exemplo 2, "Injetando ar no corpo", só se pode dizer: tão radical contravenção de ordem moral e regras gerenciais do cuidar em enfermagem, não só como procedimento inadequado - sobretudo "incorreto na técnica de prestar assistência e cuidados de enfermagem"(11). Como medida tecnicamente desajustada, provoca reação violenta pela flatulência com excesso de ar no corpo do cliente e, assim, violando a promoção da segurança e conforto através do cuidado de enfermagem. Enquanto trato absurdo a envolver erro consistente com a negligência e o descuido pode, só por si, causar maiores danos pelo procedimento desajustado no cuidado ao cliente, uma criança-bebê, que não pode se queixar e tampouco se defender. Tal absurda situação, conforme registros autorais ${ }^{(12)}$, fere significados essenciais de princípios básicos de enfermagem ${ }^{(7 ; 10)}$, e contrapõe-se às lídimas regras de atenção à criança [Cf. Notas sobre Enfermagem para Classes Laboriosas - Capítulo Cuidando de Bebês $\left.{ }^{(12)}\right]$. Ademais, tal violação em atividades de enfermagem é pedagogicamente contrária ao que se aprende do princípio nightingaleano da demonstração pelo exemplo, único a fundamentar de base a responsabilidade assistencial e "os deveres profissionais da enfermeira no exercício de sua arte"(7;11-12).

Acerca do Exemplo 3 "Passando o plantão no elevador", só se pode mesmo dizer: tão radical violação de regras processuais 
inadmissíveis quanto às "responsabilidades fundamentais da enfermeira na assistência de enfermagem", mormente na coordenação, gerenciamento e organização em planos de atividades em jornadas do trabalho assistencial. Tão absurda situação constitui flagrante contraposição aos procedimentos profissionais e normas de Ética Profissional(13-14). As discussões típicas, - na Graduação e Pós-Graduação -, expõem tal procedimento como assunto normal (comezinho/habitual) que pode fazer crer que é o mais regular. De todo modo, assunto crucial contraposto aos procedimentos de ordem técnica e processual, moralmente desajustado pelas interconexões com chefia e liderança no trabalho assistencial. Ademais, assunto plural pelos aspectos adversos, inusitados, contrapostos às disposições normativas, regras e critérios reguladores de "obrigações e deveres da enfermeira" institucionalizados em Serviços e Divisões de Enfermagem $^{(15)}$. Aliás, dada a abrangência pelos riscos, invoca decididamente a fiscalização da prática, pois tão potencial de danos para os clientes sob cuidados de enfermagem (tanto que esta repercutiu com ato de suicídio do doente confuso).

Os registros ou assentamentos em relatórios específicos sobre fatos em plantões assistenciais impõem a devida vigilância de enfermagem, imperativa para enfermeiras/os nas trocas de incumbências em jornadas e responsabilidades nas atribuições que Ihes cabem no trabalho assistencial. Em experiências de tempo anterior, de modo algum se poderia admitir e assumir riscos tangíveis a tal atividade tipo "passando o plantão no elevador". Secundando as autoras dos três exemplos de situações-problema, cabe afirmar que

A arte de enfermeira pode até estar presente [nas atividades descritas], porém não efetivamente e significativamente destacada no que concerne à expressão do que se entenda por arte verdadeiramente profissional, pois de todo modo, [a atuação da enfermeira nas três situações] está efetivamente marcada e vinculada a desvios da função assistencial na Enfermagem ${ }^{(5)}$.

Particularmente, pelo Exemplo 3, e pelos relatos obtidos em salas de aulas, sobre a formação do perfil profissional e ensino da "arte" do que-fazer, do saber-fazer e do poder-fazer da enfermeira, somente restou evidente que aspectos adversos de fatos assistenciais como esse - (especificamente dado) - seriam consistentes com os compreendidos/aprendidos relatórios de plantão. Porém, os assentamentos e registros em livros de ocorrências já não merecem mais o relevante significado anteriormente reconhecido, ou talvez não alcancem os destaques de pertinência quanto às atribuições da enfermeira nas passagens de plantões.

É lamentável, sobretudo quando não se pode recorrer mais do apoio de comunicação descrita de fatos ocorridos nos serviços assistenciais, e quando só se pensa em ganhar tempo "passando o plantão no elevador". Contraditoriamente, são violados "responsabilidades e deveres da enfermeira" face aos princípios de organização e coordenação de atividades e atribuições nos cenários do trabalho assistencial institucionalizado $^{(16)}$. Com efeito, o que seria admissível e de "obrigatoriedade técnica e ética", seria atender precipuamente às regras e disposições de conceitos aliados às noções e normas de notória responsabilidade da enfermeira nas competências legais de "coordenação, chefia, gerência e liderança das equipes"(14-16) que compõem o trabalho assistencial, na área da Enfermagem.

\section{DO CONCEITO DE INERÊNCIA E DEFINIÇÃO DA PALAVRA ENFERMEIRA}

Pelos esclarecimentos imprescindíveis a reconsiderações pontuais, cumpre-me enfatizar o Sistema Nightingale de Enfermagem Moderna ${ }^{(12)}$, e colocar que a identidade profissional emerge definida nas proposições nightingaleanas, a partir de 1860, na concepção magistral de "Notas sobre Enfermagem - o que é e o que não é"(17) (tradução brasileira). E acrescente-se: definição como arte de enfermagem justamente, de permeio com atributos profissionais descritos quando da implantação, em Londres, da Escola Nightingale para Treinamento de Enfermeiras, no Hospital Saint Thomas, o que sucedeu em plena Era Vitoriana, após a Guerra da Criméia (1854 a 1855 - a paz foi assinada em 1956). Considere-se que, no plano de um "sistema de idéias" - caso do pensamento nightingaleano - as proposições e definições assumem caráter doutrinário de unidade teórica em um todo conceitual em sua inteireza (tal como sucede nos Sistemas Filosóficos de grande relevo - Descartes, Kant, Hegel).

Então, já desde a criação da Escola Nightingale, - conforme consagrada autora e biógrafa(12) -, as proposições aliadas à função assistencial da enfermeira, surgem de início já singularmente definidas. E "porque Florence não desejava que suas novas enfermeiras fornecessem (a quem quer que fosse), o menor motivo de crítica, as competências da enfermeira são singularmente definidas"(12), e se destacam no que couber às suas responsabilidades e atribuições:

Promover a saúde e manter a vida mediante novo estilo do que-fazer e como ajuda aos indivíduos e seus familiares acometidos pelas enfermidades ou carentes de se manterem sadios e, acima de tudo, pelo seu saber-fazer em âmbito da arte $\underline{\text { de cuidar como a mais bela das belas artes }}^{(12 ; 17)}$ (grifo nosso)

Então, no dizer da mesma autora ${ }^{(12)}$, a simples ideia de descrever a identidade profissional impõe atributos indispensáveis às enfermeiras, porque também,

Florence Nightingale é, acima e além de tudo, uma pedagoga, não se pode deixar de acrescentar que as atitudes éticas e as condutas profissionais da enfermeira se conformam a uma mística vocacional a primar na demonstração pelo exemplo, nas instruções sobre saúde, e decisivamente com base em princípios básicos de cuidados de enfermagem ${ }^{(12)}$. (grifo nosso)

De fato, não se podem minimizar traços e conceitos nightingaleanos relativos à identidade profissional da enfermeira. Por aquela época de crises econômicas, políticas e sociais envolvendo a Reforma Sanitária no Sistema Inglês ${ }^{(12)}$, as atribuições da enfermeira - de tão substantivamente ajustadas dispensam adjetivos da função de prestar os cuidados de enfermagem aos clientes, (enfermos ou sadios carentes de ajuda e situados em 
diferentes locais) -, e conformam-se à arte peculiar de cuidar em enfermagem e à específica identidade profissional. Porém, as modificações e ajustamentos conceituais acompanham as grandes crises. Com as mudanças e crises políticas nas primeiras décadas do século XX, nos Estados Unidos, ocorreram mudanças e avaliação do Sistema de Saúde e do processo de formar profissionais. Na evolutiva histórica, surgem ajustamentos nos comportamentos da enfermeira, mormente em relação à enfermagem assistencial como praticada naquele país. Na atenção às novas instâncias assistenciais, princípios reguladores da saúde, saneamento básico e vida tipo modus vivendi em plano comunitário se ajustam, também, com novas competências na definição do papel da enfermeira. Os níveis e princípios de saúde pública fundamentam procedimentos técnicos e critérios reguladores nos atendimentos institucionalizados, nos domicílios e nos consultórios distritais de assistência à saúde nas comunidades. E, então, conforme famoso relatório norte-americano ${ }^{(18)}$, "com os resultados das investigações aplicáveis à avaliação do processo educacional de formar enfermeiras surgem novas regras de condutas na prática assistencial de enfermagem"(18).

Não precisamos de detalhes. Dada a evolutiva do pensamento - ordem do pensar e do ser - conforme novos requisitos da educação da enfermeira em nível universitário, novas exigências da área assistencial, a liderança educacional e associativa, nos Estados Unidos, decide-se por efetuar outras avaliações relativamente ao processo educacional de formar o perfil da enfermeira, nos aspectos da atuação em cenários de campo prático. Nessa contingência, no início dos anos 1920, o interesse educacional abrange a descrição de ajustes nas competências profissionais do que-fazer, do saber-fazer e do poder-fazer da enfermeira, com novos atributos consistentes aos termos de ciência, arte e ideal(19). Assim, sob nova tonalidade os nexos epistemológicos e os princípios básicos de cuidados de enfermagem ${ }^{(10 ; 19)}$ passam a exigir compreensão coerente com noções de substancialidade e causalidade justapostas ao processo do conhecer e do aprender-a-ser enfermeira, e no modo consistente à teoria do conhecimento ${ }^{(20)}$.

Desde então, competências e responsabilidades da enfermeira, no bojo dos novos atributos, passam a ser tratadas como pertinentes e imprescindíveis à nova definição de "Enfermagem - ciência, arte e ideal"(19). Com isso, a identidade profissional acrescida de novas competências e novos termos distintivos do papel e ações da enfermeira, emerge tangível a conceitos adequados ao desenvolvimento científico e tecnológico e à definição da profissão nos planos de trabalho nas instituições da estrutura social. Tudo a ver com a saúde de clientes nos domicílios e coletividades, e relativamente às instruções sobre saúde e no viver e conviver em plano de dimensão e extensão comunitária.

Cumpre esclarecer, no que couber à unidade do todo e nas partes, à Enfermagem como ciência interessam alianças com o progresso científico e avanços tecnológicos; à Enfermagem como arte, no estilo expressivo da atuação em plano da prática concreta, não se podem prescindir de regras estéticas e tampouco de leis a regular o exercício da profissão de enfermeira. Quanto ao notório estilo estético e assistencial do profissionalismo peculiar do que-fazer da enfermeira, valendo os aspectos tangíveis aos significados da Enfermagem como ideal, é absolutamente irrecusável a atenção aos valores idealísticos de natureza ético-filosófica, como concernentes à educação e à formação do perfil profissional em âmbito de Arte da Enfermeira ${ }^{(3 ; 17)}$.

\section{DOS ASPECTOS DESTACADOS DE CONTRIBUIÇÕES SIGNIFICATIVAS}

Nesse sentido, vale reiterar: o que mais me impele a esta contribuição tem a ver, precisamente, com o plano de pensar e ser enquanto comprometida com interesses Sobre Enfermagem - Ensino e Perfil profissional ${ }^{(21)}$. E, no que pesem aos três exemplos de situações-problema, apreciadas analiticamente nos aspectos adversos, tudo parece mais grave quanto ao ensino e perfil da enfermeira brasileira. Quanto às reconsiderações pontuais, em plano de real concreto, posso endereçar os interessados a uma citação bem conhecida: A vida vale pelo uso que dela fazemos. Pelas obras que realizamos (José Inginieros). Citação que se aplica bem às condições históricas para a definição de estratégias assistenciais e concepções pedagógicas relativas ao que se possa entender por identidade profissional. Na vida e no trabalho, pelas aquisições no processo educacional de caráter disciplinar, permanente, continuado, consegue-se acumular competências para o exercício responsável da profissão que se tenha, e podem-se ganhar benefícios do cultivo do compromisso social ao longo da vida. Inegavelmente as crises sociais e as mudanças em dados espaço e tempo históricos impõem, por sua vez, ajustamentos congêneres à historicidade de condutas da vida e às necessidades de acesso ao dito bem-comum, assim como tudo o mais relativo à provisão e prestação de cuidados na saúde, e nos processos de ensino e formação do perfil profissional em termos de proposta da educação.

Por detrás de tudo existem justos patamares e parâmetros modelares a diligenciar atos e condutas dos quais ganham sentido as rotas do caminhar no ensino de formar o perfil profissional, tanto quanto no viver e no trabalhar apropriados ao domínio do Saber/Conhecimento aliado às percepções e representações do que seja assumido como identidade da enfermeira. Na área da Enfermagem, vale sobremodo o modus operandi no cotidiano da profissão e, acima de tudo, os significados de qualidade assistencial na praxis em função de prestar o cuidado de enfermagem - objeto de estudo e de trabalho - na intencionalidade subjetiva da enfermeira em prol da construção ou reconstrução de bases fundamentais da prática assistencial e como tangível ao direito legal e regras de exigência quanto aos atributos de responsabilidade social.

Contudo, face às três adversas situações assistenciais que postulamos tipo de prática de risco, e que, afinal, são assemelhadas a outras tantas, veiculadas ao público nas edições da mídia, tenho dúvidas de que ainda se possa distinguir e definir - (por quanto tempo?) - a Identidade Profissional na Enfermagem.

Aqui no Brasil, nos idos de 1920, em meio às crises políticas, econômicas e sociais, afetando a saúde e a vida da população brasileira, a concepção do Sistema Nightingaleano de Enfermagem Moderna ${ }^{(12)}$ chegou-nos no bojo da Missão Técnica de Cooperação para o Desenvolvimento da Enfermagem no Brasil, 
chefiada pela Enfermeira norte-americana Sra. Ethel Parsons, a qual, através de diagnóstico situacional em relatório específi$\mathrm{CO}^{(22)}$, legou às enfermeiras brasileiras pontos demarcadores do surgimento da Enfermagem Brasileira e, assim, a denotação do que se deveria entender por identidade profissional.

Conforme o Relatório Parsons ${ }^{(22)}$, a identidade profissional da enfermeira é plasmada em base de princípios da saúde pública $^{(23)}$. Note-se especial destaque, - secundando autoras brasileiras $^{(24)}$-, quando ela (Sra. Parsons) se expressa sobre pontos distintivos do surgimento da Enfermagem Brasileira:

A enfermeira de saúde pública tornou-se a figura central na luta sanitária mundial no começo do século XX. E sendo a saúde muito mais do que um simples assunto para estudo, tratando-se de alimentação, repouso, ar puro e recreio de que carecem o indivíduo e comunidades, assim as doutrinas sanitárias têm valor principalmente quando reforçadas pela contribuição individual. Era necessário, pois, achar-se [aqui no Brasil] um Instrutor Sanitário - tendo este sido encontrado na enfermeira de saúde pública. ${ }^{(22-23)}$ (grifo nosso)

Tudo foi permanecendo no continuum do tempo. Vale destacar, à conta de conferência - proferida em 1979 - intitulada Reflexões sobre a Prática da Enfermagem ${ }^{(25)}$, o que se registra e que se precisa saber sobre a Identidade Profissional na Enfermagem. Tenha-se em vista a colocação inicial:

A prática resume o significado de uma profissão na sociedade. Porque nela se consubstancia a realização do compromisso social, o qual, sendo obrigatório e coletivo, garante à profissão sua continuidade no tempo. De fato, a permanência de uma profissão através da história só é possível mediante adaptações contínuas às novas expectativas e necessidades da sociedade, oriundas que são do desenvolvimento científico e da conseqüente evolução técnica. Esses ajustamentos aos imperativos sociais caracterizam-se em dado momento por uma crise, que se resolve mediante a redefinição do papel profissional $^{(25)}$. (grifo nosso)

Essa conferência não precisa de detalhes. Ela é rica quanto à crise no sistema de saúde e efeitos sobre a assistência aos clientes, pelos fatores influentes às competências e responsabilidades profissionais, sem dispensar atributos e demandas de ajustamentos à identidade profissional da enfermeira. À época, no intuito de elucidar aspectos da assistência aos usuários, foi bem discutida a expropriação da saúde. E também as modificações na atenção de clientes dos domicílios para os programas institucionalizados, e com a efetiva assistência hospitalar relevada em detrimento da saúde pública. Crise dominada pelas especializações, sofisticação de equipamentos, complexidade de procedimentos técnicos, e despersonalização da assistência nas relações entre assistentes e assistidos. O encarecimento da assistência à saúde (medicamentos, equipamentos, serviços de pessoal e prestação de cuidados) demandou novas regras de classificação e credenciamento de instituições de saúde, com novos critérios de coordenação de pessoal de enfermagem em termos previdenciários. Hospitais e instituições públicas deterioram-se por insuficiência de recursos materiais e humanos, com prejuízos para assegurar-se a posição da Enfermagem na estrutura social e na extensão de cobertura de saúde a toda a população ${ }^{(26)}$. O surgimento das clínicas privadas amplia a crise com novos requisitos de funcionamento e monitoração por seguros de saúde, questão agravada por fatores afetando cenários da saúde pública, e da qual não escapa nem a formação dos recursos humanos de saúde ${ }^{(27)}$.

Desde então, a identidade profissional da enfermeira passa por ajustamentos contínuos (basta recorrer à literatura de enfermagem dos anos 1979 em diante ${ }^{(25-26)}$. Tudo muda com novas competências e atividades em contexto prático, e porque o que importa não é mais "o que a enfermeira sabe, ensina ou delega" mas o que ela faz no âmbito de seu papel e posição na estrutura dos serviços assistenciais ou em função de novas regras e disposições legais. Até as enfermeiras professoras, às vezes, presas de perplexidades, não se sentem seguras quanto a novas estratégias pedagógicas aliadas às novas concepções de saúde. Diga-se aqui, a questão dos cuidados primários de saúde(28) jamais foi claramente resolvida: mudaram nomes dos programas assistenciais, porém não mudaram a atenção efetiva no atendimento dos usuários, com sérias implicações para a população como um todo. O pior de tudo, - e posso estar equivocada (!?) -, com a mudança de atividades práticas, incoerentemente, foi mudando a típica e mais habitual linguagem profissional no interesse da área da Enfermagem, prejudicando o sentido de essência e distintivos significados da própria profissão de enfermeira.

A conta do assentado, a identidade profissional da enfermeira continua padecente dos efeitos de crises sociais, mormente em crises da saúde, e sempre acompanhada de debates sobre modificações curriculares, novos esquemas pedagógicos e exigências para os treinamentos nos cenários da saúde. Atualmente, já não se faz concessão à posição da enfermeira pela definição poético-simbólica tipo atuação de Florence Nightingale - Dama da Lâmpada - e à sua expressiva performance na Guerra da Criméia ${ }^{(29)}$, para exemplificar aqui, "como na magistral atenção enquanto ela se dirigia pelos hospitais de campanha em condutas de observação e vigilância nos cuidados prestados aos enfermos $^{\prime \prime 29)}$. Na poesia de Longfellow ${ }^{(29)}$, pode-se averiguar dita visão poético-simbólica na primaz identidade profissional da enfermeira:

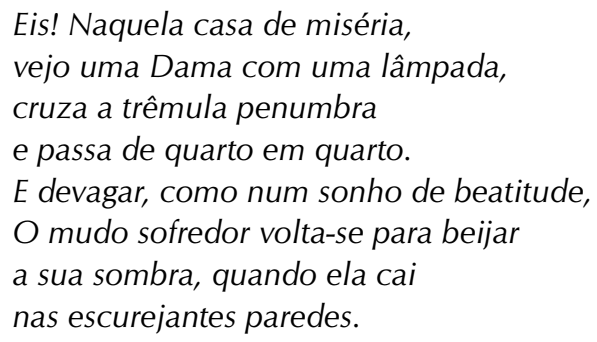

Eis! Naquela casa de miséria, vejo uma Dama com uma lâmpada, cruza a trêmula penumbra e passa de quarto em quarto.

E devagar, como num sonho de beatitude,

O mudo sofredor volta-se para beijar

a sua sombra, quando ela cai

nas escurejantes paredes.

Nessa poesia, se reproduz a primeira expressiva e emblemática compreensão histórica da definição da Identidade Profissional na Enfermagem. Porém, no final do século XIX, a própria Sra. Nightingale ${ }^{(30)}$, - depois de ter-se pronunciado sobre a Enfermagem ${ }^{(7 ; 17)}$ como "a mais bela das belas artes" -, tratou de descrever a definição da enfermeira nos seguintes termos: 
A enfermeira deve ter método, dedicação, capacidade de observação, amor ao trabalho, devoção ao dever (que é o serviço ao bem-comum), a ternura da mãe, a ausência de pedantismo (que é nunca pensar que atingiu a perfeição ou que nada existe de melhor). Ela deve possuir interesse tridimensional em seu trabalho: - 1) interesse intelectual nos casos assistidos; 2) interesse afetivo pelo paciente; e 3) interesse técnico/prático no cuidado e na cura do paciente. Ela não deve olhar os pacientes como se feitos para as enfermeiras, mas para as enfermeiras como se feitas para os pacientes ${ }^{(30)}$. (grifo nosso)

Essa definição foi estendida ao mundo. Com os 153 anos do Sistema Nightingale e os 90 anos do Modelo Parsons, mesmo aqui no Brasil, mudaram as coisas no modus operandi e questões do trabalho assistencial, mormente nas estratégias pedagógicas de formar o perfil profissional peculiar à atuação na arte de cuidar da enfermeira. Mas, permanecem distintivos traços desta "arte profissional" de inerência inegável aos princípios básicos de cuidados de enfermagem, - pela observação e vigilância dos clientes -, e acima de tudo, pelas condutas de prestar ajuda e cuidados, em atos e operações profissionais da mística nightingaleana, e que jamais deveriam ser apagados da memória de enfermeiras/os.

\section{POR UMA CONCLUSÃO}

A transmissão do corpus histórico-doutrinária desta arte insigne a todas as partes no mundo, graças às proposições da modernidade do que-fazer, de saber-fazer e de poder-fazer, veio a consagrar-se em belíssima profissão de cuidar e ajudar aos clientes, tal é o caso da Enfermagem. Justa razão para seus conceitos de base fundamental jamais serem minimizados, independentemente de condições adversas, e em qualquer tipo de prática de risco. No Brasil, mediante padrões educacionais e disposições de leis profissionais ${ }^{(16)}$, conseguiu-se definir essencialmente em efetiva formação universitária a identidade profissional da enfermeira, segundo os parâmetros do Modelo Parsons ${ }^{(22)}$.

Então, assim, à conta de todo o exposto, - por último, mas não por fim -, com as três situações assistenciais ${ }^{(5)}$, exemplares de condições nocivas e adversas aos resultados de prática assistencial eficaz para o sentido dos cuidados de enfermagem, a identidade profissional da enfermeira, pode-se afirmar -, ainda se apresenta, às vezes, adulterada quando não se consegue mais aliar a formação do perfil profissional à justaposição dos parâmetros do dito Modelo Parsons ${ }^{(22)}$. Tenha-se em consideração a primaz proposição parsoniana:

Primeiro, e sempre, "devem as enfermeiras de saúde pública aprender seu dever de executar ordens médicas", inteligentemente notificando sintomas e condições encontradas na situação dos enfermos, e prestar cuidados aos doentes a domicílio, ensinando aos enfermos e suas famílias os princípios de prevenção das doenças e de uma vida sadia ${ }^{(22)}$. (grifo da autora)
É inegável, pois, aí mesmo nesse parâmetro estabelecido com a implantação do Serviço de Enfermeiras de Saúde Pública e fundação da Escola de Enfermeiras do Departamento Nacional de Saúde Pública (DNSP), apesar de avançado em princípios de saúde pública já emergia um paradoxo epistemológico quanto ao dever ético e certo subsidiarismo consistentes às ações da enfermeira aliadas ao poder médico. Atualmente, completados os 90 anos de sua fundação, a EEAN/UFRJ (19232013), como berço matricial do Sistema Nightingale de Enfermagem Moderna ${ }^{(31)}$, conseguiu minimizar repercussões do dito paradoxo, um tanto danoso à própria evolução da Educação na Enfermagem ${ }^{(21)}$. Mas, apesar das crises na educação e saúde, com a força de leis do exercício da profissão, a Identidade Profissional na Enfermagem conseguiu ressaltar-se com a Reforma Universitária de 1968 (Lei No. 5.540/68) e, principalmente, graças aos parâmetros científicos do II PBDCT 1974 ${ }^{(32)}$ (Cf. Decreto No. 70.553/72). E, também, porque muito se deve às contribuições significativas, firmeza de poder de alta liderança acadêmica e associativa, incluídas as Escolas e Faculdades de Enfermagem e a ABEn Nacional.

Então, pelas crises políticas e sociais dos anos 1970, e os termos da economia energética e ambiental em todo o mundo, as discussões educacionais para a formação dos profissionais em nível universitário, desencadearam-se com exigências de inclusão obrigatória do ensino e prática da pesquisa, a ver com a formação dos estudantes (Graduação e Pós-Graduação) para a cadência de passos compatíveis com os avanços científicos e tecnológicos. No Brasil, esta questão vinha já se adiantado, desde os anos 1960, com os continuados debates sobre as Leis de Diretrizes e Bases da Educação Nacional (LDB), razão de introdução de modificações curriculares, tanto mais imperiosas com a implantação da Pós-Graduação stricto sensu na realidade brasileira, e com o Curso de Mestrado na EEAN/ UFRJ em 1972.

Dada a contemporaneidade dessa questão, não é preciso analisar detalhes. É do conhecimento público a forma como a atual crise política e econômica ganha mais notoriedade, no Brasil, com reivindicações e contestações invocando os direitos de cidadania e acesso a tudo que se refere ao bem-comum. Atentamente quanto aos aspectos críticos da educação de enfermeiras/os, na EEAN, cumpre-me considerar que, a partir de 1978, foi implantado novo esquema arquétipo denominado de Currículo de Novas Metodologias - SESU/MEC ${ }^{(33)}$.

Sumariamente, já não se pode negar o quanto se deve à pesquisa e aos fatores influentes correlatos, na formação profissional de enfermeiras/os, e basta ter em conta os qualitativos e quantitativos da produção e divulgação do Saber/ Conhecimento Profissional e no modo como vem se modificando a atuação profissional, afetando também estratégias assistenciais e pedagógicas, mormente em que pesem os próprios esforços em prol da formação universitária. Afinal, falando somente pela EEAN/UFRJ, toda a questão como assim colocada vem se culminando, nos termos dos Núcleos e Linhas de Pesquisa, mais decisivamente a partir de 1993.

Todavia, se todos os objetivos alcançados ganharam força, em relação à nova tonalidade da identidade profissional, pelo cultivo dos Núcleos e Linhas de Pesquisa, também 
não se pode esquecer o quanto se deve, acima de tudo, à prática de investigações e produções científicas e, assim, às mudanças curriculares decorrentes dos planos Sobre Enfermagem - Ensino e Perfil Profissional21. Planos que giram em torno do que-fazer, do saber-fazer e do poder-fazer dos novos atuantes engajados na prática profissional. E, aqui, faz sentido toda atenção aos termos de competências afinadas ao Marco Conceitual do atual Currículo de Graduação em Enfermagem e Obstetrícia (EEAN/UFRJ) ${ }^{(33)}$. Que eu saiba, o Currículo de Novas Metodologias estendeu-se e influenciou a formação de enfermeiras/os em todos os cantões da realidade brasileira. E, tal como penso, há explicitamente uma nova definição de identidade profissional nos termos deste arquétipo curricular. Ou seja:

A ENFERMEIRA atua como fulcro de um PROCESSO do qual emerge a prática total da ENFERMAGEM entendida como a CIÊNCIA e a ARTE DE AJUDAR a indivíduos, grupos e comunidades, em SITUAÇÕES nas quais não estejam capacitados a prover o AUTO-CUIDADO para alcançar seu nível ótimo de SAÚDE ${ }^{(33)}$.

As distorções de ótica são comuns em épocas de crises a ver com grandes mudanças, como esta atual apelando à globalização e competitividade nas ações do viver, do conviver e do trabalhar ${ }^{(2)}$. Cumpre a enfermeiras/os, pelos ditames do "dever ético e obrigações legais", e porque socialmente comprometidos com a prática assistencial na Saúde e na Enfermagem, independentemente de seus engajamentos em locus operandi, esclarecerem e assumirem suas justas posições de cuidar e nas atitudes de ajudar aos clientes. Isto, desde que são responsáveis por suas atividades e atuação face às situações propiciadoras ou adversas, em âmbito de trabalho na prática assistencial, e de toda forma situações envolvendo necessidades fundamentais dos seres humanos e a preocupação em atendê-las.

Nesse sentido, diante de restantes dúvidas conceituais sobre a Identidade Profissional na Enfermagem, e tendo diante de si próprios os significados da dignidade de sua profissão, talvez sejam hora e vez de as/os enfermeiras/os se perguntarem: Afinal, para onde vai a chama exemplar da mística implícita na Lâmpada Nightingaleana?

(Eu, pessoalmente, costumo pensar: se os colegas de profissão não quiserem mais se haver com buscas de respostas para esta ingente questão, só perguntando mesmo ao emblemático Espírito de Enfermagem e, depois, tentar rastrear a inteligência por caminhos de visão filosófica potencial de um novo histórico re-começo).

\section{REFERÊNCIAS}

1. Carvalho V, Sauthier J. Annaes de Enfermagem: informatização das publicações de 1932 a 1954. Rio de Janeiro: Anna Nery/UFRJ; 2002.

2. Carvalho V. Para uma Epistemologia da Enfermagem: tópicos de crítica e contribuição. Rio de Janeiro: UFRJ/ EEAN; 2013.

3. Caccavo PV, Carvalho VA. Arte da Enfermagem: efêmera, graciosa, e perene. Rio de Janeiro: Anna Nery/UFRJ; 2003.

4. Morin E. Introdução ao Pensamento Complexo. Lisboa: Instituto Piaget; 1990.

5. Carvalho V, Figueiredo NMA, Tyrrell MAR. A Lex-Art da Enfermagem e do Cuidar: A (Inter)dependência entre o fazer e pesquisar. In: Livro de resumos do $10^{\circ}$. Seminário Nacional de pesquisa em Enfermagem-SENPE; 1999 maio 24-27; Gramado (RS), Brasil. Brasília: Associação Brasileira de Enfermagem; 1999. p. 103.

6. Santos SMG. O legado de Vicente Licínio Cardoso: as leis básicas da Filosofia da Arte. Rio de Janeiro: UFRJ; [198-].

7. Nightingale F. Notes on Nursing: what it is and what it is not. London: Duckworth; 1970.

8. Carvalho V, Paim L. Acerca da Assistência de Enfermagem: considerando significado e destaques. Esc Anna Nery Rev Enferm 1999;3(3):37-51.

9. Conselho Federal de Enfermagem (Brasil). Resolução $n^{\circ}$. 9, de 1975. Código de Deontologia de Enfermagem. Diário Oficial da União 29 mar 1976; Seção 1.
10. Henderson V. Princípios Básicos sobre Cuidados de Enfermagem. Rio de Janeiro: ABEn; 1962.

11. Souza EF. Novo Manual de Técnica de Enfermagem: procedimentos e cuidados. Rio de Janeiro: EEAN/UB; 1957.

12. Seymer LR. Florence Nightingale: Pioneira da Enfermagem e Precurssora da Emancipação Feminina. São Paulo (SP): Edições Melhoramentos, [s.d].

13. International Council of Nurses. The ICN Code of Ethics for Nurses. Geneva: ICN; 2006.

14. Conselho Federal de Enfermagem (Brasil). Resolução COFEN nº. 311/2007. Código de Ética dos Profissionais de Enfermagem. Diário Oficial União 9 fev 2007; Seção 1.

15. Conselho Regional de enfermagem. Consolidação da Legislação e Ética Profissional. Série Cadernos Enfermagem COREN SC. Florianópolis: COREN; 2010.

16. Conselho Federal de Enfermagem. Decreto $N^{\circ}$. 94.406/87, de 08 de junho de 1987. Regulamenta a Lei $n^{\circ}$. 7.498, de 25 de junho de 1986, que dispõe sobre o exercício da Enfermagem, e dá outras providências. Diário Oficial da União 26 de jun 1986.

17. Nightingale F. Notas sobre Enfermagem: o que é e o que não é. São Paulo: Cortez; 1989.

18. Goldmark J. Nursing and nursing education in the United States: report of a survey. New York: Macmillan; 1923.

19. Vidal ZC. O Triângulo da Enfermeira. Ann Enferm 1934;1(3):11-2. 
20. Hessen J. Teoria do Conhecimento. Coimbra: Sucessor; 1960.

21. Carvalho $\mathrm{V}$, organizador. Sobre Enfermagem: ensino e perfil profissional. Rio de Janeiro: UFRJ/EEAN; 2006.

22. Parsons E. A Enfermagem Moderna no Brasil [fac-simile]. Esc Anna Nery Rev Enferm 1997;(1):9-24.

23. Carvalho V. A Enfermagem de saúde pública como prática social: um ponto de vista crítico sobre a formação da enfermeira em nível de graduação. Esc Anna Nery Rev Enferm 1997; 1 (n. ${ }^{\circ}$ esp.):25-41.

24. Paiva MTNSS, Silva MTN, Oliveira IRS, Araújo MJS, Carvalho $V$, Santos I. Enfermagem Brasileira: contribuição da ABEn. Brasília: ABEn-Nacional; 1999.

25. Carvalho V, Castro IB. Reflexões sobre a Prática da Enfermagem. In: Anais do $31^{\circ}$ Congresso Brasileiro de Enfermagem; 1979 out 5-11; Fortaleza(CE), Brasil. Brasília(DF): SESU/MEC; 1999. p. 51-59.

26. Oliveira MIR. Enfermagem e Estrutura Social. In: Anais do XXXI do $51^{\circ}$ Congresso Brasileiro de Enfermagem; 1979 out 5-11; Fortaleza(CE), Brasil. Brasília(DF): SESU/MEC; 1999. p. 9-32
27. Landmann J. Racionalização da assistência médica no Brasil. Saúde Debate 1977;1:44-55.

28. Organización Mundial de la Salud. Atención Primaria de Salud. Conferencia Internacional de Alma-Ata URSS. 1978 sept. 6-12. Alma-Ata, URSS. Ginebra(SWZ): OMS/ UNICEF; 1978.

29. Dolan JA. Nursing in Society: a historical perspective. 3.th ed. Philadelphia: W. B. Saunders; 1973.

30. Seymer LR. The Selected Writings of Florence Nightingale. New York: Macmillan; 1954.

31. Carvalho AC. Associação Brasileira de Enfermagem: 1926/1976 - Documentário. Brasília: ABEn; 1976.

32. Coura JR, organizador. Plano Básico de Desenvolvimento Científico e Tecnológico - Pesquisa Fundamental e Pós-Graduação/Ciências da Saúde. Brasília: MEC/CNPq; 1974.

33. Carvalho V, Castro IB, Paixão, SS. Um Projeto de Mudança Curricular no Ensino de Enfermagem em nível de Graduação que favorece aos Propósitos Emergentes da Prática Profissional. In: Sobre Enfermagem: ensino e perfil profissional. Rio de Janeiro: UFRJ/EEAN; 2006. p. $73-100$ 